-FINAL DRAFT-

\title{
RADIOGRAPHIC ABNORMALITIES, BLADDER INTERVENTIONS, AND BLADDER SURGERY IN THE FIRST DECADE OF LIFE IN CHILDREN WITH SPINA BIFIDA
}

\author{
Adam J Rensing, Konrad M Szymanski, Rosalia Misseri, Joshua D Roth, Shelly King, Katherine Chan, \\ Benjamin M Whittam, Martin Kaefer, Richard C Rink, Mark P Cain
}

\author{
Affiliation: \\ Indiana University, Division of Pediatric Urology \\ 535 Barnhill Drive, Suite 150 \\ Indianapolis, IN 46202 \\ (317) 944-7458 (Phone) \\ (317) 944-7481 (Fax) \\ arensin@gmail.com
}

This research did not receive any specific grant from funding agencies in the public, commercial, or notfor-profit sectors.

Introduction/Objective:

Spina bifida (SB) patients are at increased risk for hydronephrosis $(\mathrm{HN})$, bladder storage and emptying problems, and renal failure that may require multiple bladder surgeries to address. We use early renal/bladder ultrasound (RBUS) and fluoroscopic urodynamic images (FUI) to guide therapies (clean intermittent catheterization (CIC), anticholinergic use (AC), and/or surgical interventions (SI)). We analyzed initial and 10-year radiologic findings, renal function (RF), and CIC, AC and SI rates for children followed proactively and consistently.

Materials/Methods:

We retrospectively reviewed all born with SB between 2005 and 2009, presenting to our institution within 1 year of birth. Outcomes at 8-11 years old included final RBUS results, CIC use, AC use, any SIs prior to final follow-up, and final RF. We excluded those without follow-up past age 8, and/or no RBUS or FUI within first year of birth. All RBUS and FUI were performed at our institution. Imaging was independently reviewed by 4 pediatric urologists blinded to radiologists' interpretation. McNemar's test was used to compare initial findings (RBUS results, FUI, CIC, AC) with final outcomes at 8-11 years of age (RBUS, CIC, AC, SI, and RF). FUI was too infrequent at the final (8-11 years) window, and not included. Serum creatinine and cystatin- $\mathrm{C}$ were used to estimate GFR.

Results:

Of 98 children, we excluded 16 without adequate follow-up (left referral area), and 20 for lack of available imaging within 1 year of birth (born elsewhere). 62 children remained for analysis: (48\% male, $76 \%$ shunted). Median age at last follow-up was 9.6 years. Upon initial imaging, $74 \%$ of children had HN ( $\geq$ SFU grade 1$)$, this decreased to 5 $\%$ at 10 years $(\mathrm{p}<0.0001)$. Initially, $9 \% \mathrm{had} \geq \mathrm{SFU}$ grade $3 \mathrm{HN}$, this decreased to $2 \%(\mathrm{p}=0.13)$. CIC and AC

This is the author's manuscript of the article published in final edited form as:

Rensing, A. J., Szymanski, K. M., Misseri, R., Roth, J. D., King, S., Chan, K., ... Cain, M. P. (2019). Radiographic abnormalities, bladder interventions, and bladder surgery in the first decade of life in children with spina bifida. Pediatric Nephrology, 34(7), 1277-1282. https://doi.org/10.1007/s00467-019-04222-w 
increased from $61 \%$ and $37 \%$, to $87 \%$ and $86 \%$, respectively ( $\mathrm{p}=0.001$ and $<0.0001$, respectively). With followup, $55 \%$ had a SI and $23 \%$ an augmentation. Of children with a serum creatinine/cystatin-C at 8-11 years old, one had confirmed CKD (stage 2).

Discussion:

This study was limited by a small sample size, retrospective nature, and selection bias toward patients with prolonged follow-up. Possible confounders, i.e. bladder capacity/compliance and desire for continence were not analyzed and may influence SI.

Conclusions:

Despite a high incidence of HN initially among children with SB, this was low grade and resolved in the first decade of life. Additionally, the 8-11 year incidence of kidney disease and upper tract changes was low in this cohort due to aggressive medical management. 
Introduction:

Renal failure is less common than it was historically in the spina bifida (SB) patient, contributing to the longer expected survival of SB patients [1]. Using early, frequent monitoring with renal-bladder ultrasound (RBUS), flurourodynamic imaging (FUI), and serum studies, we are attempting to determine early signs of pending renal failure. Clean intermittent catheterization (CIC), anticholinergics (AC), and surgical interventions (SI) are used proactively and/or expectantly to avoid what was once considered inevitable [2-4]. Although this success is laudable, what is unclear is the incidence and significance of radiologic abnormalities in infancy and later childhood. Further, there are no reliable methods of predicting who will develop chronic kidney disease (CKD) and/or require urologic surgical intervention (SI).

Despite the controversies between expectant and proactive management in the urologic literature, most agree that routine and early clinical monitoring with periodic RBUS with routine or "as needed" urodynamic testing helps to identify those patients needing early intervention [5-11]. For those patients considered at risk for obstructive nephropathy, the three tools at a pediatric urologist's disposal for intervention include CIC, AC, and/or SI. These are considered efficacious and well-tolerated [2, 12-15].

Rather than expectant management, our group employs a proactive approach. For those born with SB, we institute early CIC (three times each day) based on elevated postvoid residuals following myelomeningocele closure. We believe early CIC is easier for patients and families to accept and tolerate, while leaving open the option of ending CIC if residuals are consistently below $10 \mathrm{ml}$ for 48 hours prior to leaving the hospital. RBUS is performed within the first week of birth, and flurourodynamics are ideally pursued at 3 months of age.

The incidence and significance of radiologic abnormalities within 1 year of life in the SB population is unknown. Also with routine follow up, it is unclear whether initial findings upon RBUS and/or FUI persist. This information may be clinically useful, and potentially reassuring when counseling families of children born with SB.

In this study, we sought to evaluate radiologic studies performed, and CIC and AC status within 1 year of life, and later at 8-11 years of age (in addition to SI and RF) in all patients initially managed at our institution with the diagnosis of SB. We hypothesized a high incidence of initial hydronephrosis (HN) and vesicoureteral reflux (VUR), 
with improvement in these parameters and an overall low incidence of chronic kidney disease (CKD) later in life in the setting of modern medical management. 
Material and Methods

After IRB approval under IRB number 1605024102, we collected a cohort of children with SB followed at our institution who were born between August 2005 and August 2009. We collected all subsequent radiology studies performed at our institution. Those without either RBUS or FUI available for review within 1 year of birth were analyzed as a separate group. We presumed these (20) patients were either born elsewhere, and moved after first year of life, or were late referrals due to a lack of knowledge. We evaluated patient demographics and clinical characteristics, focusing on RBUS findings, FUI radiologic findings, CIC use, and AC use within 1 year of birth. For outcomes, we collected RBUS, CIC use, and AC use by 8-11 years of birth, SI by 8-11 years of age, and serum creatinine and cystatin-C, with calculated GFR.

All relevant RBUS and FUI images were independently reviewed by four pediatric urologists and blinded to radiologists' interpretation. Each renal unit on RBUS was assigned a grade of HN by each reviewer as described in the SFU grading scheme [16]. All FUIs were graded for degree of VUR (grade 0-5 per renal unit), bladder shape (round, oblong, or trabeculated), and open or closed bladder neck prior to void [17]. We then made final determinations of HN or VUR grade based upon majority consensus with mean grade if equal dissent was noted.

All charts were reviewed for any evidence of CIC or AC use, both in the first year of life, and then at 8-11 years of life to assess for 10 year outcomes. A three year window was used to assess for 10 year outcomes to maximize study enrollment, while ensuring similar follow-up length. The last outcome in the time-window was used when multiple visits occurred. At 8-11 years of life, we collected all available serum creatinine and cystatin-C values with associated measured height, gender, creatinine, and BUN. Using the bedside Schwartz and CKD-Epi CC equations, we sought to most accurately estimate GFR, and CKD stage[18, 19].

For each patient in the cohort, we collected initial predictors (RBUS findings, FUI findings, CIC use, AC use) and final outcomes (RBUS findings, CIC use, AC use, SI incidence, and RF). To assess for potential selection bias, we compared baseline characteristics and 10 year outcomes for those with and without initial imaging as a subgroup analysis. We compared the incidence of $\mathrm{HN}$, bilateral $\mathrm{HN}$, and high grade $\mathrm{HN}$ in the initial study (predictor) and the final study (outcome) using McNemar's test to correct for correlations within the sample (i.e. changes were compared within each patient, rather than for the group as a whole). Again, using McNemar's test, we compared the 
incidence of CIC use, AC use, and SI initially (predictors), and then at the final time point (outcomes). Next, we evaluated SI differences by HN status, VUR status, and initial vesicostomy status (present or not present). Catheterizable channels were most commonly performed for ease of independent CIC. Vesicostomies were performed for refractory upper tract deterioration despite maximal medical management. A critical p-value of 0.05 was used to assess for statistical significance. Lastly, we evaluated RF at the final time point (8-11 years of age) using both the bedside Schwartz equation and the CKD-Epi CC equation (when a serum cystatin-C was available). 
Results

Of 98 patients, we excluded 16 without follow-up past 8 years old, and 20 for lack of either RBUS or FUI in the first year of life, leaving 62 children for analysis. In this group, $48 \%$ were male, $66.1 \%$ had lumbar or lumbosacral defect and $76 \%$ were treated with a ventriculoperitoneal shunt for hydrocephalus (Table 1). In addition, $52 \%$ were community ambulators. Median follow-up time was 9.6 years.

We then compared those with (62) and without (20) imaging in the first year of life (Table 1). There was a higher proportion of patients with a diagnosis of lipomeningocele $(\mathrm{p}=0.02)$ in the group without imaging. The two groups were otherwise similar in makeup other than age at initial radiologic evaluation. When comparing hydronephrosis incidence, VUR status, CIC/AC rates, surgical incidence, and estimated GFR, we found no meaningful differences in any of these outcomes However, there was a higher rate of $\mathrm{AC}$ use in those with initial imaging $(\mathrm{p}=0.01)$. Those (20) patients without imaging in the first year of life were likely not recognized until sometime (months, or years) after birth, given the higher proportion of lipomeningocele.

\section{Ultrasound}

Fifty-seven children (92\%) in the cohort had a renal bladder ultrasound in the first year of life (Table 2). Of the 15/57 (26 \%) with no evidence of HN on the initial RBUS, three (20\%) subsequently underwent a vesicostomy. All of these vesicostomies were performed after the first year of life for worsening bladder compliance despite CIC/AC. Three (20\%) of those without initial HN were ultimately treated a bladder augmentation (Table 3 ).

Within the first year of life, $74 \%$ of children had some degree of $\mathrm{HN}$ ( $\geq$ grade 1 ), which decreased to $5 \%$ at 10 years $(\mathrm{p}<0.0001)$ (Table 3$)$. Initially, $9 \%$ had SFU grade 3 or higher $\mathrm{HN}$, with $2 \%$ demonstrating these grades at 10 years $(\mathrm{p}=0.13)$.

The most common finding upon initial ultrasound was low grade (SFU grade 1-2) HN (37/57, $65 \%$ ). In these patients, $11 \%$ had a vesicostomy performed and $24 \%$ underwent bladder augmentation. Few patients had initial high grade (grade 3-4) HN (5, $9 \%)$. Of these, 2 (40\%) were treated with a vesicostomy and $1(20 \%)$ with a bladder augmentation. Only 1 of these patients had persistent HN (high grade). This patient had no interval SIs, the $\mathrm{HN}$ resolved with an empty bladder, and there was no increase in grade from the initial antenatal ultrasound. Regardless of initial HN status, 23 (40\%) had no bladder surgery (vesicostomy, catheterizable channel, 
augmentation, or bladder chemodeinervation) performed by 8-11 years of age. Presence and grade of HN upon initial RBUS were not associated with risk of surgery.

\section{Flurourodynamic Images}

Fifty-nine patients (95\%) had FUI within the first year of life, with 46/59 (78\%) having no evidence of VUR. Of these, $5(11 \%)$ required vesicostomy. 20/46 (44\%) did not require any SI.

Of the 13 patients $(22 \%)$ with VUR on their initial study, roughly half $(6,46 \%)$ had high grade VUR (grade 3 or above). Three patients (50\%) with initial high grade VUR subsequently underwent a vesicostomy. One patient (14 \%) with initial low grade VUR underwent a vesicostomy. 5 patients (11\%) without evidence of VUR received a vesicostomy. When compared to those without VUR on their initial study, those with VUR had an increased risk of vesicostomy, but this was not statistically significant $(31 \%$ vs. $11 \%, p=0.10)$. There was no clear trend toward no bladder surgery for those without vs. with VUR (44\% vs. $23 \%, \mathrm{p}=0.21$ ). Similarly, these patients had similar rates of bladder augmentation ( $31 \%$ vs. $22 \%, \mathrm{p}=0.48)$.

\section{Clean Intermittent Catheterization and Anticholinergic Use}

CIC and AC increased from $38(61 \%)$ and $23(37 \%)$ in the first year of life to $54(87 \%)$ and $53(86 \%)$ at 10 years, respectively ( $\mathrm{p}=0.001$ and $<0.0001$, respectively) (Table 2$)$.

\section{Surgical Intervention}

With diligent follow-up, 34 (55\%) patients had at least one SI, with 14 (23\%) undergoing bladder augmentation. All patients treated for vesicostomy were due to failure to achieve a safe bladder despite maximal medical therapy. We first compared those initially treated with a vesicostomy with those that were not. We saw no difference in the rates of catheterizable urinary channels, bladder augmentation, onobotulinum toxin injection, or hydronephrosis on final imaging. There was an increased risk for bladder augmentation in the vesicostomy group, but this did not reach statistical significance $(\mathrm{p}=0.21)$. There was an increased risk of ureteral reimplantation in the vesicostomy group ( $\mathrm{p}=0.012)$, which may be due to the higher rate of early VUR in this group.

We then focused on those that were initially treated with a vesicostomy. $40 \%(4 / 10)$ went on to have a bladder augmentation (with catheterizable channel). One patient received a catheterizable channel only, and 2 had a 
vesicostomy takedown (without catheteriziable channel), with no further SI. At 8-11 years of age, $30 \%(3 / 10)$ continue to drain their bladder with a vesicostomy. Only $30 \%$ of the vesicostomies were performed before 1 year of age. All those treated with an initial vesicostomy now either remain with a vesicostomy or are CIC dependent (via urethra or catheterizable channel). Conversely, of the 52 patients that did not receive a vesicostomy, 11 (21\%) void spontaneously, and have not required any surgery (including onobotulinum toxin). Those treated with a vesicostomy trended towards an increased risk of requiring a bladder augmentation $(40 \%, 4 / 10$ vs. $19 \%, 10 / 53$, $\mathrm{p}=0.21)$. Those that remained with their vesicostomy at 10 years $(30 \%)$, were due to parental/family preference for ease of care.

\section{Renal Function}

Thirty-three children (53\%) in the cohort had a serum creatinine and height available at final follow-up. Using the bedside Schwartz formula, we found a median eGFR of $126 \mathrm{ml} / \mathrm{min} / 1.73 \mathrm{~m} 2$ (IQR 102-157). All values were $\geq 90$ $\mathrm{ml} / \mathrm{min} / 1.73 \mathrm{~m} 2$. Twenty children with available serum cystatin-C in the $8-11$ age range had a median GFR of 100 $\mathrm{mL} / \mathrm{min} / 1.73 \mathrm{~m} 2$ (IQR 89-112). Of those, 5 had a GFR 60-89 mL/min, but only one showed evidence of renal scarring on ultrasound. None showed evidence of albuminuria. In other words, only 1 patient had definitive evidence of stage $2 \mathrm{CKD}$. No children required hemodialysis nor renal transplant. 


\section{Discussion}

We present 10-year results of renal and bladder outcomes for children with SB. We found many had early HN (72 $\%)$. However, the majority of these findings were unilateral (52\%), and/or low grade (88 \%). Vesicoureteral reflux was less common (22\%). Over half of the children (57\%) underwent bladder surgery in the first 10 years of life. We found that a vesicostomy, a marker of a hostile bladder, tended to be a positive predictor of later bladder augmentation, but this was not statistically significant (4/10 (40\%), vs. 10/53 (19\%), p=0.21). No child developed renal failure.

A previous retrospective review of 84 children with SB imaged at age 6 months or less, found only $7 \%$ had $\mathrm{HN}$, much lower than our finding [11]. In this study, patients were categorized into "high" or "low" risk based upon evidence of retention or HN. Those considered high risk at any point received further evaluation with voiding cystourethrogram and urodynamics study, and appropriate intervention, including, but not limited to CIC, AC, vesicostomy, and/or antibiotic prophylaxis for VUR. With diligent follow-up, there was a $45 \%$ conversion rate from low to high risk, prompting the above stated studies and intervention(s). Tarcan et al. confirmed in their study that those once considered low risk, can at any time become high risk, necessitating urodynamics and further treatment $(32 \%)[6]$.

Wang et al. reviewed nationwide trends in chronic renal insufficiency (CRI) and urologic surgery over time within the SB population [20]. Interestingly, SB admissions with the diagnosis of CRI has progressively increased from 6 \% in 1998 to $12 \%$ in 2011. Yet, admissions related to urologic surgeries in this population remained stable from $2.0 \%$ in 1998 to $1.8 \%$ in 2011 . This study assessed a large administrative dataset of 427,616 SB hospital admissions, but remains difficult to interpret, given reliance upon accurate diagnostic and procedure codes.

Alabi et al. recently reviewed the Ntional Spina Bifida Registry (2009-2013) for surgical procedures and other health outcomes (fecal continence, urinary continence, skin breakdown, and ambulatory status) [21]. They noed that $81.5 \%$ (3801) had surgical data. Interestingly the most frequent procedures were neurologic, with the urologic typically occurring later in life. Overall, the rates of fecal and urinary incontinence and skin breakdown increased with age, whereas the ability to ambulate declined with age. Also the incidence of urologic surgery remained roughly $10 \%$ of total surgeries, regardless of whether myelomeningocele or nonmyelomeningocele. This study was 
different in it's large number of patients and more generalized surgical data. In contrast, our study strictly followed patients from birth at our instituions, and focused upon urologic imaging and surgical procedures.

As mentioned, our study included those with initial imaging (RBUS or FUI) within the first year, and consistent follow up until at least age 8 . To check for bias, we compared those with and those without imaging in the $1^{\text {st }}$ year. Those without imaging in the first year (possibly born elsewhere or discovered/referred later) were more likely to have lipomeningocele (statistically significant), but otherwise fairly similar in radiologic, surgical, and renal function outcomes. This would suggest that the consistent, long-term follow up is likely more important than obtaining early imaging.

Limitations of our study include the relatively small cohort as only 68 of these had perinatal radiology study. In addition, patients' charts were retrospectively reviewed. Despite our centralized, standardized follow-up model with a regularly scheduled multidisciplinary clinic visits, some patients may be seen at other institutions for their care. In addition, this is relatively short-term follow-up and may be insufficient length of time to observe deterioration of renal function. Differences between providers undoubtedly exist and were not evaluated in our study. Our study also did not include urodynamic findings (not easily available), and patients' and families' desire for continence. As we did not assess the indications for surgery, both of these factors very likely contributed toward a decision to perform bladder surgery. 


\section{Conclusion}

These data are an important contribution to the urologic care of patients with spina bifida and will be useful in counseling families. We found that although hydronephrosis is common upon the initial ultrasound, it is usually low grade, and not associated with an increased rate of surgical intervention in the first decade of life. Those treated with a vesicostomy trended towards an increased risk for bladder augmentation (relative risk 2.1, absolute risk increase of $21 \%$ ). Finally, about half (55\%) had SI in the first decade of life for variable reasons. Routine, regular

clinical follow up may be a driver toward long-term renal health with prompt evaluation, and, if necessary, early medical or surgical intervention. 
References

1. Shin M, Kucik JE, Stiffel C, Lu C, Shaw GM, Canfield MA, Correa A., Improved survival among children with spina bifida in the United States. J Pediatr, 2012. 161(6): p. 1132-7. DOI: 10.1016/j.jpeds.2012.05.040.

2. Lapides J, Diokno AC, Silber SJ, Lowe BS. Clean, Intermittent Self-Catheterization in the Treatment of Urinary Tract Disease. J Urol, 2017. 197(2, Supplement): p. S122-S124. DOI: 10.1016/j.juro.2016.10.097.

3. Snow-Lisy, DC, Yerkes, EB, and Cheng EY. Update on Urological Management of Spina Bifida from Prenatal Diagnosis to Adulthood. J Urol, 2015. 194(2): p. 288-96. DOI: 10.1016/j.juro.2015.03.107.

4. McGuire, EJ, Woodside JR, Borden TA, Weiss RM. Prognostic value of urodynamic testing in myelodysplastic patients. J Urol. 1981. 126(2): p. 205-9.

5. Kaefer M, Pabby A, Kelly M, Darbey M, Bauer SB. Improved bladder function after prophylactic treatment of the high risk neurogenic bladder in newborns with myelomentingocele. J Urol, 1999. 162(3 Pt 2): p. 1068-71.

6. Tarcan T, Bauer S, Olmedo E, Khoshbin S, Kelly M, Darbey M. Long-term followup of newborns with myelodysplasia and normal urodynamic findings: Is followup necessary? J Urol, 2001. 165(2): p. 564-7. DOI: 10.1097/00005392-200102000-00070

7. Tarcan T, Onol FF, Iker Y, Simsek F, Ozek M. Does surgical release of secondary spinal cord tethering improve the prognosis of neurogenic bladder in children with myelomeningocele? J Urol, 2006. 176(4 Pt 1): p. 1601-6; discussion 1606. DOI: 10.1016/j.juro.2006.06.036

8. Edelstein RA, Bauer SB, Kelly MD, Darbey MM, Peters CA, Atala A, Mandell J, Colodny AH, Retik AB. The long-term urological response of neonates with myelodysplasia treated proactively with intermittent catheterization and anticholinergic therapy. J Urol, 1995. 154(4): p. 1500-4.

9. Kasabian NG, Bauer SB, Dyro FM, Colodny AH $<$ Mandell J, Retik AB. The prophylactic value of clean intermittent catheterization and anticholinergic medication in newborns and infants with myelodysplasia at risk of developing urinary tract deterioration. Am J Dis Child, 1992. 146(7): p. 840-3.

10. Timberlake MD, Kern AJ, Adams R, Walker C, Schlomer BJ, Jacobs MA. Expectant use of CIC in newborns with spinal dysraphism: Report of clinical outcomes. J Pediatr Rehabil Med. 2017 Dec 11;10(34):319-325. DOI: 10.3233/PRM-170464.

11. Hopps CV, Kropp KA. Preservation of renal function in children with myelomeningocele managed with basic newborn evaluation and close followup. J Urol, 2003. 169(1): p. 305-8. DOI: 10.1097/01.ju.0000040590.35948.bc

12. Diokno AC, Sonda LP, Hollander JB, Lapides J. Fate of patients started on clean intermittent selfcatheterization therapy 10 years ago. J Urol, 1983. 129(6): p. 1120-2.

13. Lee JH, Kim KR, Lee YS, Han SW, Kim KS, Song SH, Baek M, Park K. Efficacy, tolerability, and safety of oxybutynin chloride in pediatric neurogenic bladder with spinal dysraphism: a retrospective, multicenter, observational study. Korean J Urol, 2014. 55(12): p. 828-33. DOI:

10.4111/kju.2014.55.12.828

14. Veenboer PW, Hulsman J, Chrzan RJ, Kuijper CF, Dik P, deKort LM, de Jong TP. Behavioral Effects of Long-Term Antimuscarinic Use in Patients with Spinal Dysraphism: A Case Control Study. The Journal of Urology, 2013. 190(6): p. 2228-2232. DOI: 10.1016/j.juro.2013.06.036

15. Giramonti KM, Kogan BA, Halpern LF. The effects of anticholinergic drugs on attention span and shortterm memory skills in children. Neurourol Urodyn, 2008. 27(4): p. 315-8. DOI: 10.1002/nau.20507

16. Fernbach SK, Maizels M, Conway JJ. Ultrasound grading of hydronephrosis: introduction to the system used by the Society for Fetal Urology. Pediatr Radiol, 1993. 23(6): p. 478-80.

17. Lebowitz RL, Olbing H, Parkkulainen KV, Smellie JM, Tamminen-Möbius TE. International system of radiographic grading of vesicoureteric reflux. International Reflux Study in Children. Pediatr Radiol, 1985. 15(2): p. 105-9.

18. Schwartz GJ, Muñoz A, Scheider MF, Mak RH, Kaskel F, Warady BA, Furth SL New equations to estimate GFR in children with CKD. J Am Soc Nephrol, 2009. 20(3): p. 629-37. DOI: 10.1681/ASN.2008030287

19. Ng, DK, Schwartz GJ, Schneider MF, Furth SL, Warady BA. Combination of pediatric and adult formulas yield valid glomerular filtration rate estimates in young adults with a history of pediatric chronic kidney disease. Kidney International, 2018. DOI: 10.1016/j.kint.2018.01.034

20. Wang HH, Lloyd JS, Weiner JS, Routh JS. Nationwide Trends and Variations in Urological Surgical Interventions and Renal Outcome in Patients with Spina Bifida. J Urol. 2016. 195(4, Part 2): p. 1189-1195. DOI: $10.1016 /$ j.juro.2015.11.033 
21. Noreen B. Alabi, Judy Thibadeau, John S. Wiener, Mike J. Conklin, Mark S. Dias, Kathleen J. Sawin, Rodolfo Valdez. Surgeries and Health Outcomes Among Patients With Spina Bifida. Pediatrics Sep 2018, 142 (3) e20173730; DOI: 10.1542/peds.2017-3730 
Table 1. Baseline characteristics and non-urologic clinical history.

\begin{tabular}{|c|c|c|c|}
\hline & $\begin{array}{l}\text { With imaging in First Year } \\
(n=62)\end{array}$ & $\begin{array}{l}\text { Without imaging in } \\
\text { First year }(n=20)\end{array}$ & $P$ values \\
\hline Male & $30(48 \%)$ & $10(50 \%)$ & 0.99 \\
\hline Myelomeningocele & $59(95 \%)$ & $15(75 \%)$ & 0.02 \\
\hline Lipomeningocele & $3(5 \%)$ & $5(25 \%)$ & \\
\hline \multicolumn{4}{|l|}{ Myelomeningocele level } \\
\hline Thoracic Defect & $3(5 \%)$ & 0 & 0.43 \\
\hline Lumbar or lumbosacral defect & $41(66 \%)$ & $11(55 \%)$ & \\
\hline Sacral Defect & $15(24 \%)$ & $4(20 \%)$ & \\
\hline Community ambulators & $32(52 \%)$ & $14(70 \%)$ & 0.20 \\
\hline Median age at first ultrasound & 10 days & 4.8 years & $<0.00001$ \\
\hline $\begin{array}{l}\text { Median age at first } \\
\text { Flurourodynamics }\end{array}$ & 19 days & 4.8 years & $<0.00001$ \\
\hline $\begin{array}{l}\text { Shunt Incidence for } \\
\text { Hydrocephalus }\end{array}$ & $47(76 \%)$ & $12(60 \%)$ & 0.25 \\
\hline $\begin{array}{l}\text { Initial Flurourodynamics } \\
\text { Findings ( } n=59)\end{array}$ & & $*$ & \\
\hline Any Vesicoureteral Reflux & $13(22 \%)$ & $*$ & \\
\hline Bilateral Vesicoureteral Reflux & $8(14 \%)$ & $*$ & \\
\hline $\begin{array}{l}\text { High grade Vesicoureteral } \\
\text { Reflux ( } \geq \text { grade } 3 \text { ) }\end{array}$ & $6(10 \%)$ & $*$ & \\
\hline Open bladder neck & $38(64 \%)$ & $*$ & \\
\hline $\begin{array}{l}\text { Oblong or trabeculated bladder } \\
\text { shape on cystogram }\end{array}$ & $26(44 \%)$ & $*$ & \\
\hline
\end{tabular}

*Patients in this cohort did not routinely get flurourodynamics. 
Table 2. Incidence of hydronephrosis, clean intermittent catheterization, anticholinergics, and bladder surgery

\begin{tabular}{|c|c|c|c|}
\hline $\mathrm{N}=57^{*}$ & First year of life & Final time point & $p$-value** \\
\hline Any Hydronephrosis & $42(74 \%)$ & $3(5 \%)$ & $<0.0001$ \\
\hline Bilateral Hydronephrosis & $22(39 \%)$ & $2(4 \%)$ & $<0.0001$ \\
\hline Any High Grade Hydronephrosis (> SFU Grade 2) & $5(9 \%)$ & $1(2 \%)$ & 0.13 \\
\hline \multicolumn{4}{|l|}{$\mathrm{N}=62$} \\
\hline Clean Intermittent Catheterization Status & $38(61 \%)$ & $54(87 \%)$ & 0.001 \\
\hline Anticholinergic Use & $23(37 \%)$ & $53(86 \%)$ & $<0.0001$ \\
\hline Bladder surgery\# & $3(5 \%)^{n}$ & $34(55 \%)$ & $<0.0001$ \\
\hline
\end{tabular}

*5 patients in this cohort did not have an ultrasound within the first year of life.

**Calculated using McNemar's test.

\# Defined as vesicostomy, vesicostomy takedown, catheterizable channel, bladder chemodenervation, or bladder augmentation.

$\wedge$ All were vesicostomies. 
Table 3. Ten-year outcomes stratified by hydronephrosis upon initial renal ultrasound $(n=57)$

\begin{tabular}{|l|r|r|r|r|}
\hline & \multicolumn{1}{|l|}{ All } & $\begin{array}{l}\text { No } \\
\text { Hydronephr } \\
\text { osis }\end{array}$ & $\begin{array}{l}\text { SFU Grade } \\
1-2\end{array}$ & \multicolumn{1}{l|}{\begin{tabular}{l} 
SFU Grade 3- \\
\hline
\end{tabular}} \\
\hline & 57 & $15(26 \%)$ & $37(65 \%)$ & $5(9 \%)$ \\
\hline $\begin{array}{l}10 \text { year } \\
\text { outcomes }\end{array}$ & $9(16 \%)$ & $3(20 \%)$ & $4(11 \%)$ & $2(40 \%)$ \\
\hline Vesicostomy & $25(44 \%)$ & $7(47 \%)$ & $16(43 \%)$ & $2(40 \%)$ \\
\hline $\begin{array}{l}\text { Catheterizable } \\
\text { bladder channel }\end{array}$ & $13(23 \%)$ & $3(20 \%)$ & $9(24 \%)$ & $1(20 \%)$ \\
\hline $\begin{array}{l}\text { Bladder } \\
\text { augmentation }\end{array}$ & $8(14 \%)$ & $4(27 \%)$ & $4(11 \%)$ & $1(20 \%)$ \\
\hline Botox injection & $4(7 \%)$ & 0 & $3(8 \%)$ & $2(40 \%)$ \\
\hline $\begin{array}{l}\text { Ureteral } \\
\text { reimplantation }\end{array}$ & $23(40 \%)$ & $5(33 \%)$ & $16(43 \%)$ & 0 \\
\hline $\begin{array}{l}\text { No bladder } \\
\text { surgery }\end{array}$ & & & & \\
\hline
\end{tabular}




\section{Conflicts of Interest}

There were no conflicts of interest amongst the authors of this manuscript. 